\title{
Impact of the Process Parameters, the Measurement Conditions and the Pre-Machining on the Residual Stress State of Deep Rolled Specimens
}

\author{
Nataliya Lyubenova ${ }^{1, *}$, Dirk Bähre ${ }^{1}$, Lukas Krupp ${ }^{2}$, Julie Fouquet ${ }^{2}$, Titouan Cronier ${ }^{2}$, \\ Jay Patel ${ }^{2}$ and Joachim Ernst Hoffmann ${ }^{2}$ \\ 1 Institute of Production Engineering, Saarland University, D-66121 Saarbrücken, Germany \\ 2 Department of Materials Science and Materials Testing, University of Applied Sciences, \\ D-67657 Kaiserslautern, Germany \\ * Correspondence: nataliya.lyubenova@xrd-eigenmann.de; Tel.: +49-157-8387-6610
}

Received: 24 May 2019; Accepted: 5 July 2019; Published: 10 July 2019

check for updates

\begin{abstract}
Mechanical surface treatments, e.g., deep rolling, are widely spread finishing processes due to their ability to enhance the fatigue strength of the treated materials with means of cold working and inducement of favorable compressive residual stresses. Despite of the clear advantages of deep rolling, the controlled generation of compressive residual stresses is still a challenging task, as the process can be influenced by the pre-machining stress state of the treated material. Additionally, the exact characterization of the induced residual stress field is impacted by the specific characteristics of the applied measurement technique. Therefore, this paper is focused on the X-ray diffraction residual stress analysis of deep rolled specimens, pre-machined to achieve rough or polished surface. The deep rolling process was realized as a single-trace to avoid the influence of the other process parameters and the resulted residual stress field on the surface and in depth was investigated. Additionally, the surface residual stress profiles were determined using two different measuring devices to analyze the impact of the different measurement conditions.
\end{abstract}

Keywords: residual stresses; X-ray diffraction; deep rolling; mechanical surface treatment; surface integrity; process chain; AISI 4140 steel

\section{Introduction}

Deep rolling is a well-known surface finishing process established in the 1930s of the last century [1-3]. It has a very wide application range, due to its simple principle [4] and the resulting high set-up flexibility. Different axis-symmetric components, e.g., crankshaft journals, aircraft wheel rims, axles, tension screws, cylinder head valves, bearings, etc., are often finished using deep rolling $[5,6]$. Treatment of complex-shaped parts is also possible, typical examples are different aircraft engine parts like turbine disks and compressor fan blades [7]. The main advantage of deep rolling when compared with, e.g., the even commonly applied shot peening process, is that along the induced cold worked layer, deep rolling generates deeper compressive residual stress (RS) field and achieves a smoother surface in contrary to shot peening. The controlled generation of compressive residual stresses is crucial for the fatigue strength of the treated material, as compressive residual stresses can prevent crack initiation and can retard crack propagation. Despite of the clear benefits of deep rolling (DR), the controlled generation of compressive RS is still a challenging task, due to several factors like the numerous of available process parameters and the stress state influenced by the pre-machining of the treated material. To date, the exact prediction of the RS state after deep rolling has still not been achieved, despite the available common knowledge about the impact of the mostly important process parameters, gathered by extensive research studies throughout the past decades [8,9]. 
The finite element analysis, being in most cases already a decisive phase of process modelling, took also its place among the scientific work on topic modelling and prediction of the process output variables by DR. Starting in the mid-1990s of the last century, many efforts were done to model DR process [10-12], using static or dynamic approaches, applying different simplification strategies and investigating several process characteristics. Despite the big progress of this relatively new scientific direction, the ultimate DR model (able to predict process output characteristics) is still not available, due to the complexity of the DR process in a manner of input variables.

In [13] was established a finite element model of the DR process, employing the commercially available software ABAQUS CAE to investigate the influence of some crucial process parameters on the resulted RS depth profiles. A flat geometry was chosen as a work piece, in order to eliminate the influence of the stress concentrators, which may occur in case of complex geometry. The DR process was modelled as single-trace (only one trace was simulated instead of treatment of complete surface). Additionally, an overlapping parameter (similar to the coverage percentage below $100 \%$ by shot peening) was defined and the results were compared with those by way of the single-trace treatment. The RS depth profiles, resulted from the simulation, were plausible and some of the characteristic features of the DR process, known from the available literature were recognizable. Nevertheless, the findings from the modelling needed to be verified. As a continuation of this research, in [14] was employed the same DR model as in [13] to investigate and verify with means of X-ray diffraction the surface RS in single and multiple trace DR. The X-ray diffraction RS measurements in the DR trace were in the most cases in a satisfactory agreement with the RS predicted by the simulation. Although, in some cases, the simulation tended to underestimate the tensile RS determined by the X-ray diffraction. The authors concluded that the available deviations did not result only due to simulation's uncertainties, but because the X-ray diffraction measurements were performed at the limit of the device's accuracy and this could be a source of ambiguity as well.

As a continuation of the research in [14], the present paper focuses on the impact of the DR process parameters, the measurement conditions and the pre-machining on the RS state of DR specimens. Some of the characteristic process parameters were varied, like the amount of the applied DR pressure, the number of overturns (similar to the coverage percentage over 100\% by shot peening) and the percentage of overlapping.

Additionally, before applying the DR, the specimens were pre-machined using different sequences to reach variable surface quality; some of the specimens were milled, other were milled and polished and the influence of the pre-machining on the RS state after DR was analyzed. It is known that the residual stress history of materials is an important factor for predicting the final RS state, as every stress state generated at the corresponding process chain stage will influence those generated at the next process chain stage, thus leading in some cases to unpredictable results.

Finally, yet importantly, the surface RS state in the DR trace was determined twice by means of two different $\mathrm{X}$-ray diffractometers at independent laboratories, where the devices possessed similar hardware features as well as comparable measuring and evaluation parameters.

\section{Materials and Methods}

\subsection{Material Data and Specimens' Preparation Procedure}

The material used in all of the experiments was a high strength quenched and tempered steel of grade AISI 4140 (USA designation) or 42CrMoS4 (DIN designation). This is a chromium-molybdenum alloy with increased Sulphur percentage for improved machinability and it is widely used in the automotive and in the aircraft industries due to its high ductility in a combination with high strength and good air corrosion resistance. It possesses the following mechanical properties: Young's modulus-210.0 GPa, yield strength—app. $1008 \mathrm{MPa}$, ultimate strength—app. $1081 \mathrm{MPa}$, fracture strain-15.0\% and necking-53.5\%. The material's heat treatment was as follows: Austenitized (hardened) at $860^{\circ} \mathrm{C}$ for $60 \mathrm{~min}$, quenched in polymer and tempered at $560^{\circ} \mathrm{C}$ for $120 \mathrm{~min}$. At the end, 
it was cooled down to room temperature in air. To prepare the specimens for the X-ray diffraction measurements, rolled (in sense of metal forming process) rods with a square profile $25 \mathrm{~mm} \times 25 \mathrm{~mm}$ were cut to a length of $40 \mathrm{~mm}$ and the top surface on which the DR was later applied was milled with the parameters shown in Table 1. The side surfaces were milled to achieve a specimen width of $20 \mathrm{~mm}$.

Table 1. Milling parameters.

\begin{tabular}{cc}
\hline Type of Milling & Perpendicular Face Milling \\
\hline Spindle speed-n & $600 \mathrm{rpm}$ \\
Feed & $100 \mathrm{~mm} / \mathrm{min}$ \\
Cutting depth & $4 \times 1 \mathrm{~mm}+2 \times 0.5 \mathrm{~mm}$ \\
Cooling lubricant & yes \\
\hline
\end{tabular}

The next part of the process chain was varying single-trace DR or DR with overlapping, performed by ECOROLL Company. The tool used was ECOROLL HG6 equipped with a hydrostatically pressurized roller burnishing sphere, which allowed the tip of the tool to move freely in the axial direction and the sphere to freely-rotate in all directions. The diameter of the sphere was $6.35 \mathrm{~mm}$ and it was manufactured from tungsten carbide. The treatment was realized with low viscosity oil. The pressure supplied by a hydraulic aggregate was kept constant during the treatment and did not exceed $40 \mathrm{MPa}$. An exemplarily scheme of such DR tool is plotted in Figure 1.

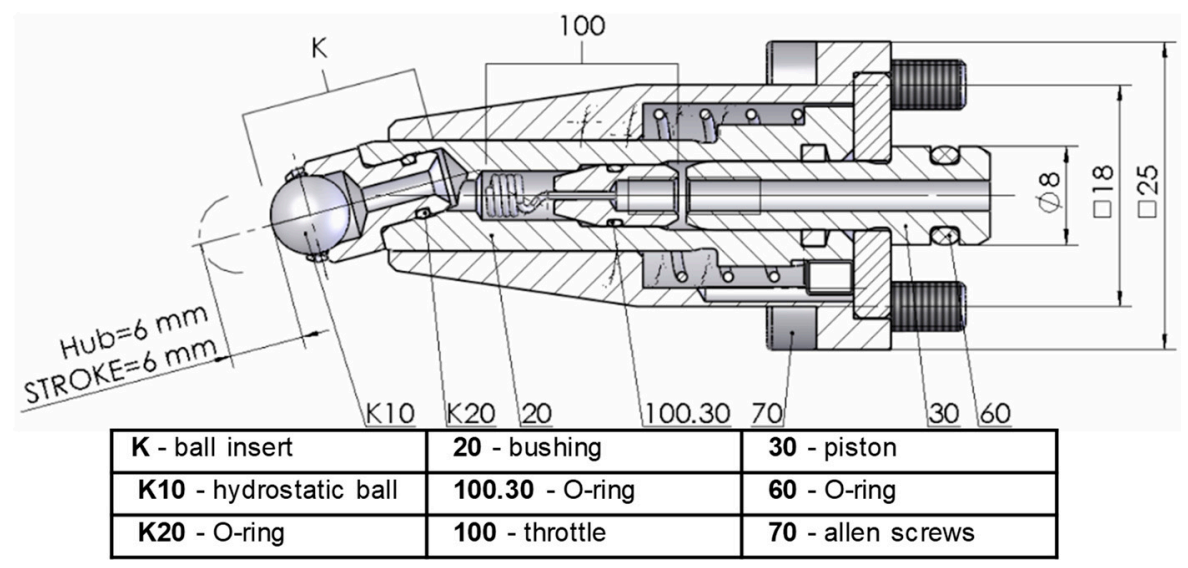

Figure 1. Scheme of deep rolling (DR) tool type HG 6.

After the milling procedure, some of the specimens were additionally ground with sandpaper (removed layer of minimum $100 \mu \mathrm{m}$ ), polished, and lastly, deep rolled. This additional procedure was accomplished in order to reduce the influence of the pre-machining (milling) on the RS state after DR. The parameters of the corresponding polishing procedure are plotted in Table 2. In order to fit the specimen's manipulator of the x-ray diffractometer, the depth of the specimens needed to be reduced from $20 \mathrm{~mm}$ to $10 \mathrm{~mm}$.

Table 2. Polishing procedure.

\begin{tabular}{cc}
\hline Parameter & Value \\
\hline Applied Force & $25 \mathrm{~N}$ \\
Velocity & $150 \mathrm{rpm}$ \\
Coarse grinding & at least $100 \mu \mathrm{m}$ removed \\
Fine grinding & SiC paper: $120 ; 320 ; 600$ and 1200 \\
Polishing & Polishing cloth Struers Delta + diamond suspension $3 \mu \mathrm{m} ;$ \\
& Polishing cloth Struers Zeta + diamond suspension $1 \mu \mathrm{m}$ \\
\hline
\end{tabular}


The varying treatment sequences build two different process chains, which differ in the DR treatment itself and in the pre-processing. In Table 3 is depicted the experimental design for both process chains with the corresponding specimens' designations and the DR process parameters. In yellow is marked the varied process parameter. The overturn parameter was defined as a multiple rolling on the same place. Based on a finite element simulation, multiple overturn was modeled and the resulted RS were investigated. By seven overturns, a saturation level was reached and therefore in this article the specimens with seven overturns were analyzed. The overlapping parameter $A$ (see Equation (1)) was defined in percentage, where $O$ is the distance between two overlapping traces defined from the middle of each trace and $a$ is the width of the trace for the corresponding DR pressure.

$$
O=(100 \%-A \%) \times a
$$

Table 3. Experimental design-DR process parameters.

\begin{tabular}{ccccc}
\hline \multirow{2}{*}{$\begin{array}{c}\text { Specimen No } \\
\text { (Milled + DR) }\end{array}$} & $\begin{array}{c}\text { Specimen No (Milled } \\
\text { Polished + DR) }\end{array}$ & PR Pressure & Overturn (o.t.) & Overlapping (o.1.) \\
\cline { 3 - 5 } & P11 & $20 \mathrm{MPa}$ & 1 & $0 \%$ \\
M12 & P8 & $40 \mathrm{MPa}$ & 1 & $0 \%$ \\
M15 & - & $40 \mathrm{MPa}$ & 5 & $0 \%$ \\
M18 & P4 & $40 \mathrm{MPa}$ & 7 & $0 \%$ \\
M19 & P2 & $40 \mathrm{MPa}$ & 1 & $75 \%$ \\
M22 & & & & \\
\hline
\end{tabular}

\subsection{Experimental Set up}

The X-ray diffraction measurements were performed in two different laboratories: At the Chair of Functional Materials, Saarland University, where a diffractometer PANalytical Empyrean was available and at the Department of Materials Science and Materials Testing, University of Applied Sciences in Kaiserslautern, where a diffractometer Seifert, XRD 3000 PTS was currently in use. These independent measurements were accomplished in order to compare the measurement parameters and the accuracy influences when using different measurement devices.

Some of the specimens treated under the process chain "milling + DR" were measured on the surface using the PANalytical Empyrean diffractometer and thereafter the Seifert, XRD 3000 PTS. This allowed comparing the surface RS determined by the both devices. The specimens treated under the both process chains ("milled + DR" or "milled + polished + DR") were measured in depth with diffractometer Seifert, XRD 3000 PTS which allowed investigating the pre-processing and DR influence by constant measurement conditions.

In Figure 2a is displayed an exemplary picture of one specimen, with corresponding geometry. Figure $2 \mathrm{~b}$ shows a microscopy image of one specimen and the position of the surface measurement path, consisting of several measurement points. The distance between the measurement points in the DR trace was $100 \mu \mathrm{m}$ to $200 \mu \mathrm{m}$ and out of the DR trace $-500 \mu \mathrm{m}$ to $1000 \mu \mathrm{m}$. The surface measurement path was defined transverse to the DR trace, i.e., in $\pm x$ direction and with $x=0$ was designated the center of the trace. In case of treatment with overlapping the $0 \mathrm{x}$-coordinate was set in the center of the overlapping trace.

The RS depth profiles were obtained in the center of the DR trace (in case of DR with overlapping, in the center of the overlapping trace), in $+z$ direction by means of successive layer removal with electropolishing. The thickness of the removed layers was variable: $10 \mu \mathrm{m}, 25 \mu \mathrm{m}$ and $50 \mu \mathrm{m}$ for a depth up to $625 \mu \mathrm{m}$ and increased to $250 \mu \mathrm{m}-500 \mu \mathrm{m}$ for depth up to $1200 \mu \mathrm{m}$. In the section "results and analysis", the longitudinal residual stress values were designated with "longRS" and the transverse ones with "trsvRS". 

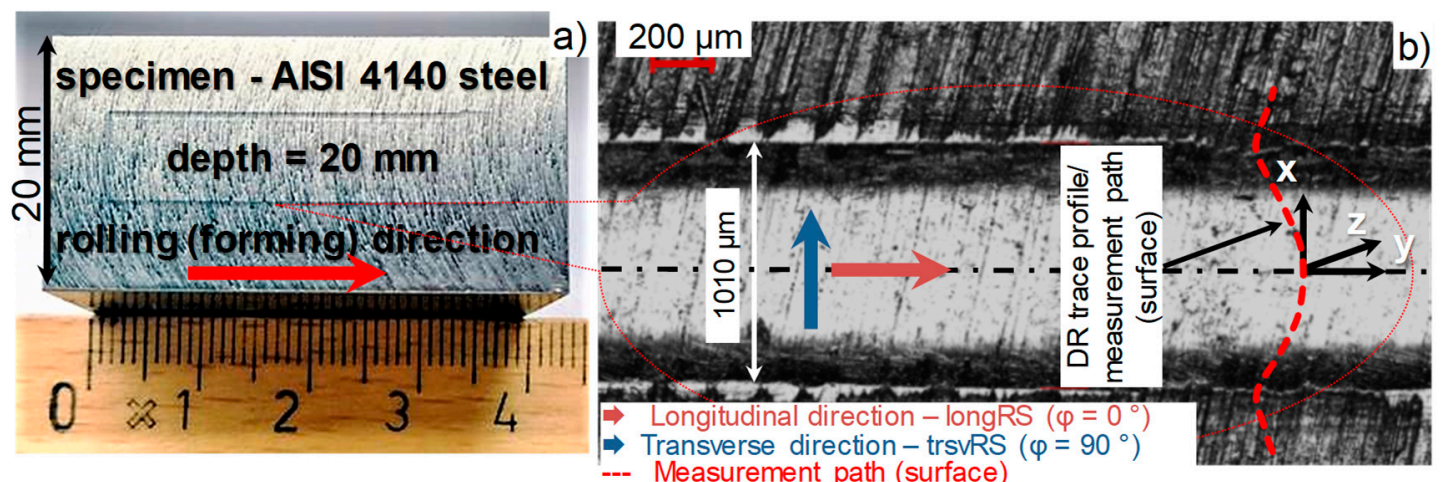

Figure 2. (a) Specimen's geometry and material; (b) microscope image of the DR trace and measurement directions.

To ensure the accuracy and the reproducibility of the measurements, several disturbing factors were considered. First, the accurate in-plane $(x-y)$ positioning of the specimen was optimized as adjusting the device's alignment camera. The in-plane ( $x-y)$ positioning was crucial due to the available stress gradients in direction transverse to the DR trace. On the PANalytical diffractometer, it was accomplished by longitudinal and transverse scanning of a $130 \mu \mathrm{m}$ thin plate and analyzing the measured diffraction peak intensity. As result of the scanning, the Gaussian shaped curve of the intensity was used to align the peak of the curve with the center of the specimen (it was assumed that the specimen was symmetrical). The difference between the position of the alignment camera and the position of the intensity peak was considered as an alignment error and hence corrected. Using this procedure, an in-plane ( $\mathrm{x}-\mathrm{y})$ positioning accuracy of $\pm 50 \mu \mathrm{m}$ was achieved.

On the Seifert diffractometer, the in-plane measuring position on the specimen's surface was set also with an alignment camera. To improve the positioning accuracy, the crosshair of the camera needed to be precisely adjusted in the center of the goniometer's operational circle. This was accomplished by using a sample with adhered fluorescent paper with a marking point on it. When rotating the sample around the z-axis, the deviation of the crosshair's position in $\mathrm{x}-\mathrm{y}$ direction was visible as a movement of the sample's marking point. The deviation was hence corrected until the position of the crosshair aligned with the center of the goniometer's operational circle. Afterwards, the position of the X-ray beam was also checked and precisely adjusted with the aid of the adjusted camera crosshair image on the fluorescent paper with the marking point.

Another disturbing factor considered was the adjustment of the specimen in vertical (z) direction to ensure that its surface lays in the center of the goniometer's operational circle. On the PANalytical diffractometer, using the available measurement gauge, the exact vertical positioning for measurements in the trace was not possible and therefore it was obtained out of the trace. Previously, white light interferometry technique (WLI) was used to determine the DR trace geometrical profile and to correct the value of the vertical position of the specimen.

On the Seifert diffractometer, the available measurement gauge was equipped with a sharper tip, thus enabling the vertical positioning for in-trace measurements. The exact in-plane position of the measuring gauge tip was ensured by producing an imprint with the tip. The imprint was compared with the current coordinates of the positioning camera and the difference between the current coordinates and those of the imprint was then corrected. Thereafter, the specimen's height adjustment was obtained. The measurement points were defined at $300 \mu \mathrm{m}$ far from the place where the gauge's tip touched the specimen's surface to avoid misleading stress values due to possible plastic deformation of the touched area.

The absolute height adjustment of the diffractometer's specimen manipulator was additionally controlled by determining the stress in iron powder. This is a standard control/adjustment procedure aiming to reach/measure no RS, as in powder state no RS can exist between the iron grains. 
One important diffractometer's feature needed to be additionally considered and this was the $\psi$ tilting possibility (limited by the device's configuration). The PANalytical goniometer was equipped with a specimen's manipulator able to tilt only in one direction. This limitation should not influence the measured values only in case the $2 \theta$ over $\sin ^{2} \psi$ distribution is linear. When measuring in a curvature (i.e., the DR trace), a geometrical $\psi$ splitting occurs [15] which causes the calculated stress value for the positive $\psi$ angles to be higher than this for the negative $\psi$ angles or vice versa dependent on the splitting direction. This can lead to shifting of the measured values, where the measured tensile stress will be shifted to higher tensile stress value and the measured compressive stress will be shifted toward higher compressive stress value. An opposite shifting can be observed when the $\psi$ splitting is in the opposite direction.

In contrary to the PANalytical Empyrean goniometer, the Seifert goniometer had the possibility to tilt in positive and in negative $\psi$ angles, which eliminates the issue discussed above.

In Table 4 are listed the hardware features of the both diffractometers as well as the measurementand the evaluation-parameters used. The hardware features of the both devices were similar, with an exception of the $\psi$ tilting degree of freedom. The measurement parameters were defined considering several criterions like achieving a reasonable intensity of the reflection peak for acceptable exposure time, ensuring good statistical reliability with means of decent $\psi$ tiltings and using a $\varphi$ oscillation during the measurement (only on Seifert XRD 3000 PTS). The $2 \theta$ measurement range was optimized during the measurements and even the narrowest $2 \theta$ measuring range delivered enough diffraction background, so that a reasonable peak to background ratio was available. Comparison measurements with all scanning ranges confirmed in this case, that narrowing the scanning range did not affect the results. The measurement time for both diffractometers differed due to different detectors used. Although, the quality and the intensity of the diffraction peaks for both systems were comparable.

Table 4. X-ray diffraction set up of diffractometers PANalytical Empyrean and Seifert, XRD 3000 PTS.

\begin{tabular}{|c|c|c|}
\hline Diffractometer & $\begin{array}{l}\text { PANalytical Empyrean, } \\
\theta-\theta \text { Configuration }\end{array}$ & $\begin{array}{l}\text { Seifert, XRD } 3000 \text { PTS, } \\
\text { Goniometer TS-4, } \psi \text {-Type } 2014\end{array}$ \\
\hline \multicolumn{3}{|l|}{ Hardware Data } \\
\hline Detector & Proportional counter & $\begin{array}{l}\text { Semiconductor line detector } \\
\text { Meteor 1D, } 2011\end{array}$ \\
\hline Radiation & $\mathrm{Cr}-\mathrm{K}_{\alpha}$ & $\mathrm{Cr}-\mathrm{K}_{\alpha}$ \\
\hline $\mathrm{K}_{\beta}$-Filter & Vanadium & Vanadium \\
\hline Primary slit & Polycapillary glass mini-lens & Polycapillary glass mini-lens \\
\hline Primary beam diameter (focused) & $0.05 \mathrm{~mm}$-manufacturer's data & $\begin{array}{l}0.05 \mathrm{~mm} \text {-manufacturer's data; } \\
0.1 \mathrm{~mm} \text { - own measurement }\end{array}$ \\
\hline \multicolumn{3}{|l|}{ Measurement parameters } \\
\hline Meas. lattice plane & $\{211\}$ & $\{211\}$ \\
\hline Diffraction angle $2 \theta_{0}$ & $156.5^{\circ}$ & $156.084^{\circ}$ \\
\hline Meas. range $2 \theta$ & $151.7^{\circ}$ to $161.3^{\circ}$ & $147^{\circ}$ to $159.5^{\circ}$ or $141^{\circ}$ to $161^{\circ}$ \\
\hline Meas. time parameter & $390 \mathrm{~s}$ & $120 \mathrm{~s}$ \\
\hline Number of $\psi$ tiltings & 7 equidistant, $0-50^{\circ}$, with $\sin ^{2} \psi$ & 27 equidistant, $\pm 50^{\circ}$, with $\sin ^{2} \psi$ \\
\hline Meas. directions $\varphi$ & $\begin{array}{l}\text { Longitudinal } 0^{\circ} \\
\text { transversal } 90^{\circ}\end{array}$ & $\begin{array}{l}\text { Longitudinal } 0^{\circ} \\
\text { transversal } 90^{\circ}\end{array}$ \\
\hline Oscillation & None & Around $\varphi$ axis $\pm 5^{\circ}$ \\
\hline \multicolumn{3}{|l|}{ Evaluation parameters } \\
\hline Evaluation software & PANalytical Stress & Analyze (up-date 2017) \\
\hline Evaluation method & $\sin ^{2} \psi$ & $\sin ^{2} \psi$ \\
\hline Elasticity const. $\frac{1}{2} \mathrm{~s}_{2}\{211\}$ & $6.10 \times 10^{-6} \mathrm{~mm}^{2} / \mathrm{N}$ & $5.81 \times 10^{-6} \mathrm{~mm}^{2} / \mathrm{N}$ \\
\hline Young's modulus E $\{211\}$ & $210,000 \mathrm{MPa}$ & $220,000 \mathrm{MPa}$ \\
\hline Poisson's ratio $v^{\{211\}}$ & 0.28 & 0.28 \\
\hline Peak positioning & Center of gravity $20 \%$ & Center of gravity $70 \%$ \\
\hline
\end{tabular}




\section{Results and Discussion}

\subsection{Residual Stress State After Pre-Machining}

The first results shown in Figure 3 include the RS state in depth of two randomly chosen milled specimens before the DR treatment, where the milling procedure was performed with identical process parameters, see Table 1. Longitudinal (longRS) and transverse (trsvRS) directions refer the direction of the later DR trace and not the cutting direction of the milling process. Considering the position and the form of milling traces on the specimen (see Figure 2), the direction of the measured residual stresses cannot be clearly designated as along or transverse to the cutting direction.

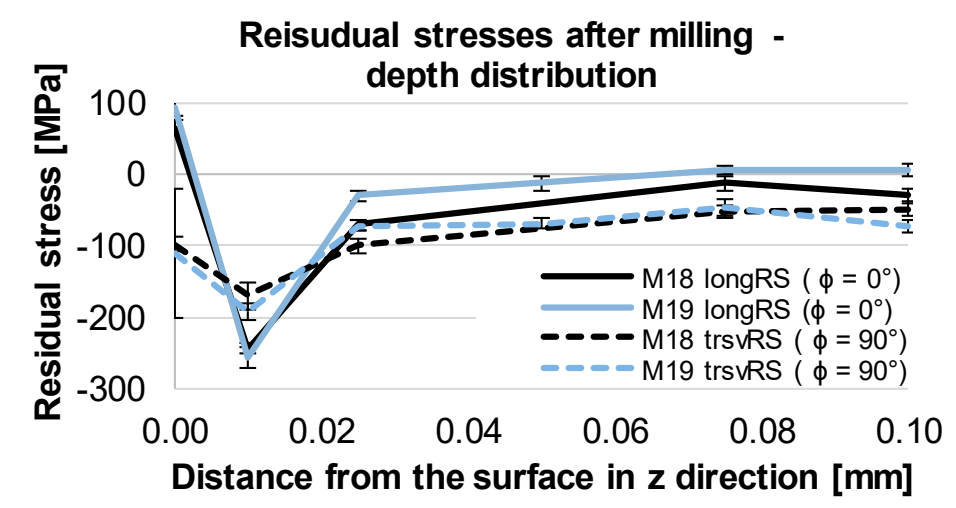

Figure 3. Residual stress depth distribution of milled specimens.

The depth profiles of the RS in longitudinal and transverse direction for the both specimens were very similar with a difference of maximum $80 \mathrm{MPa}$ at depth below $25 \mu \mathrm{m}$. Although, near the surface (up to $25 \mu \mathrm{m}$ depth), the stress values in longitudinal and in transverse directions differ up to $200 \mathrm{MPa}$. This fact has to be taken into account when investigating the surface RS state after the DR treatment, as the RS generated by the milling can affect those caused by the DR. In this particular case, it can be assumed that the pre-machining can affect the surface RS state after DR but should not have a huge impact on the RS depth distribution after DR.

\subsection{Surface RS State After Pre-Machining and DR, Influence of the Measurement Device}

As discussed in the introduction section, the characterization of the RS profiles after DR is still an issue even when the process parameters are fixed, due to some specific measurement procedure characteristics. Often, employing the same measurement techniques is not a guarantee for consistent results, as the precision and the devices' setup can vary. Therefore, the current section presents results of RS surface profiles measured on same specimens but using different diffractometers. In addition, some of the most significant DR process parameters were varied and the resulting RS profiles were compared.

In Figure 4 are plotted the surface RS distribution of DR specimens (milled + DR), where the DR pressure was varied from $20 \mathrm{MPa}$ to $40 \mathrm{MPa}$. The same specimens were measured using Seifert and PANalytical diffractometers, using measurement parameters and orientation plotted in Table 4 and in Figure 2. In the both measured directions: Longitudinal (see Figure 4a) and transverse (see Figure 4b), the difference between the values derived by the both diffractometers lay between $50 \mathrm{MPa}$ and 150 $\mathrm{MPa}$. The higher DR pressure (see specimen M15_p40) leaded to a slight shifting of the transverse RS from compressive towards tensile. The RS distribution in longitudinal direction varied from this in transverse direction for the both specimens and this is typical for the DR process, due to the in-process differing plastic stretching and shrinking in the longitudinal and transverse directions [16]. 
a)

$$
\text { longRS different diffractometers, }
$$
pressure variation

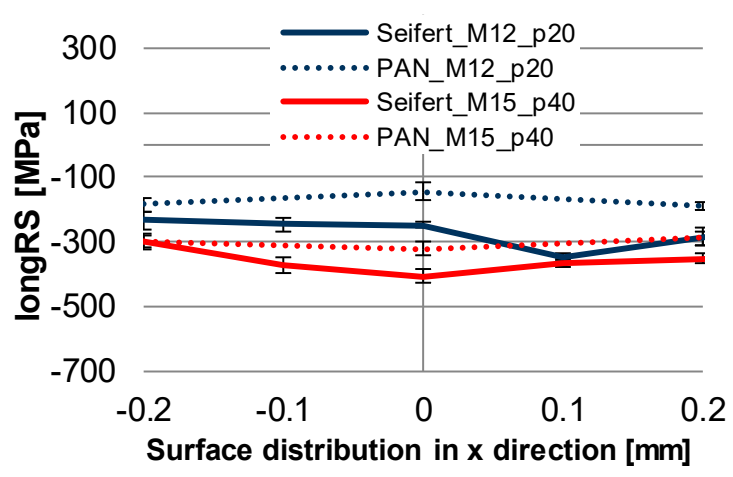

b) trsvRS different diffractometers, pressure variation

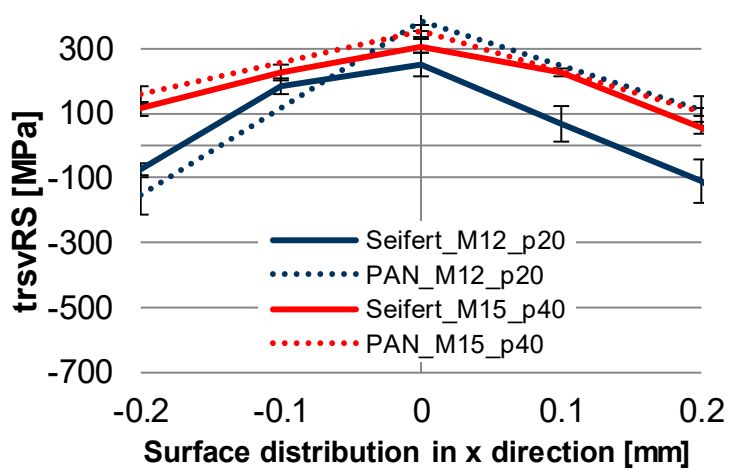

Figure 4. In-trace residual stress surface distribution in $\pm x$ direction, by variation of the measurement device (Seifert XRD 3000 PTS or PANalytical Empyrean) and the DR pressure (designation " $\mathrm{p}$ "); (a) longitudinal residual stresses (longRS) and (b) transverse residual stresses (trsvRS).

It is also visible that the stress distribution was not always as expected symmetrical to the center of the DR trace; this can be a sign of a measurement position misalignment.

Figure 5 (milled + DR state) shows the surface RS distribution in longitudinal (see Figure 5a) and in transverse (see Figure $5 b$ ) direction, by variation of the number of overturns (o.t.) or the overlapping (o.l.) percentage. The DR pressure was kept constant at $40 \mathrm{MPa}$. Here, both measurement devices deliver again similar results but some moderate asymmetry in the stress profiles in longitudinal direction (see Figure 5a) was present. The RS state in longitudinal direction after DR with 7 overturns (Figure 5a, M19_7o.t.), compared with the no overturn (Figure 4a, M15_p40) was higher compressive with values between $-400 \mathrm{MPa}$ to $-600 \mathrm{MPa}$ (single overturn: $-300 \mathrm{MPa}$ to $-400 \mathrm{MPa}$ ). The $75 \%$ overlapping (M22_75\% o.1.) compared with no overlapping (M15_p40) delivered similar results. In the transverse direction, the DR with 7 overturns (M19_7o.t., Figure 5b), compared with the single overturn (M15_p40, Figure 4b), reduced the tensile RS situated in the middle of the DR trace. The DR with overlapping (M22_75\% o.l.), compared with DR without overlapping (M15_p40) delivered similar RS profiles.

a)

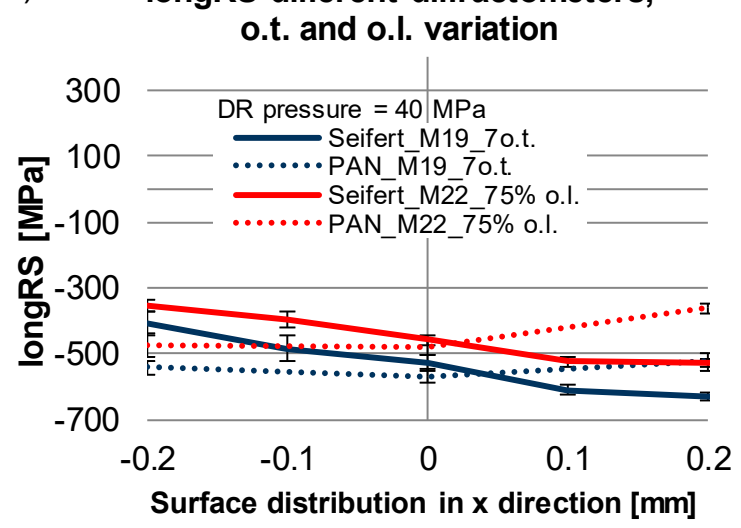

b) trsvRS different diffractometers, o.t. and o.l. variation

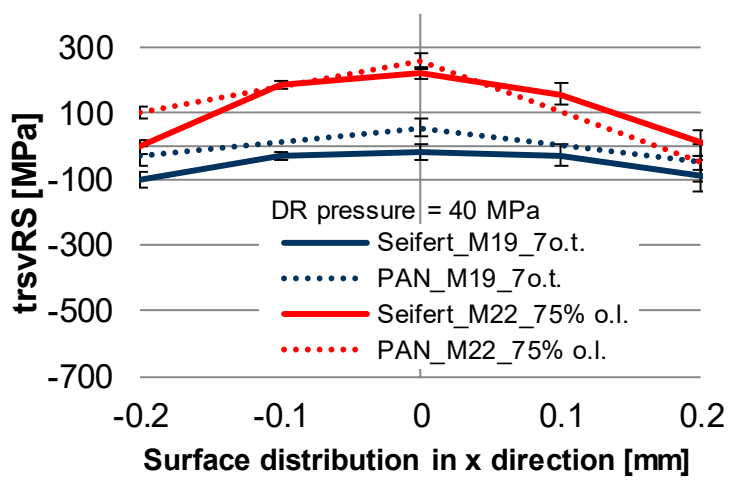

Figure 5. In-trace residual stress surface distribution of milled and DR state (designation M), by variation of the measurement devices (Seifert XRD 3000 PTS or PANalytical Empyrean), the overturn (o.t.) and the overlapping (o.l.) parameters; (a) longitudinal residual stresses (longRS) and (b) transverse residual stresses (trsvRS).

The results shown in Figures 4 and 5 confirm that, in this particular case, the employment of different measurement devices, when applying similar measurement techniques and parameters do not 
lead to a large inconsistency of the determined RS values. Nevertheless, when in general investigating very similar RS states, the observed discrepancy of up to $150 \mathrm{MPa}$ can be a crucial factor for the correct interpretation of the measured values.

\subsection{Surface RS State After DR, Influence of the Pre-Machining}

The results shown in the previous section emphasized some aspects of the measurement uncertainties that may arise when using different diffractometers. The performed in-trace measurements focused in the middle of the DR trace did not show the complete RS state impacted by the DR process. The surface measurement area was, therefore, expanded to fully cover the width of the DR trace in an amount of over $0.7 \mathrm{~mm}$. The measurement path was extended to $3 \mathrm{~mm}( \pm 1.5 \mathrm{~mm})$, as its position remained the same- - transverse to the DR trace $(-x$ and $+x$ direction). The stress determination was obtained using the diffractometer Seifert XRD 3000 PTS, with the parameters shown in Table 4.

In this section, the pre-machining treatment of the later DR specimens was varied, where specimens labeled with " $\mathrm{M}$ " were milled and deep rolled and those labeled with the " $\mathrm{P}$ " were milled, polished and deep rolled. Some changes in the RS profiles were expected due to the variable roughness (on the milled specimens much higher than on the polished ones) and the corresponding change in contact surface between work piece and tool during the initial penetration of the DR tool. The DR process parameters were varied in the same manner as in the previous section: Applied pressure, number of overturns and overlapping percentage. The RS surface profiles in both longitudinal and transverse directions were depicted.

Figure 6 represents the surface RS profiles and the trace width of specimens deep rolled with variable pressure. The width of the DR trace (designated with dotted vertical lines) increased with increasing of the DR pressure, an indication of expanding plastically deformed zone. For the used material, the process pressure from $20 \mathrm{MPa}$ to $40 \mathrm{MPa}$ can be considered as a low to high range. The further increasing of the DR pressure should not lead to greater RS state changes due to saturation level reached. By DR treatment with $40 \mathrm{MPa}$, the maximal determined surface RS was near the yield strength of the material. Considering the almost ideal plastic behavior of the material (the yield strength and the ultimate strength are very close as values), no significant raise of the RS should be expected by further increasing the DR pressure. Additional investigations of the hardness state and the x-ray diffraction peak widths (FWHM) show that the material does not prone to cold working, as after DR, no significant change of the hardness and the x-ray diffraction peak widths was observed.

The stresses in longitudinal direction are plotted in Figure 6a. Here, the highest difference exhibited the stresses of the milled vs. polished specimens treated with a DR pressure of $20 \mathrm{MPa}$. It was assumed that the polished + DR specimens should exhibit lower compressive RS than the milled + DR specimens due to the resulting difference in the contact force during treatment caused by the variable surface roughness. Considering the applied DR pressure was, in general constant, when the contact area between specimen and DR tool decreased due to high roughness of the specimen, the contact pressure increased proportionally with the decrease in contact area. This should lead to a higher amount of plastic deformation and higher compressive RS values. In contrary to this assumption, the polished + DR specimen (P11_p20) exhibit higher compressive RS than the milled + DR (M12_p20) and even than the specimens treated with 40 MPa pressure (M15_p40 and P8_p40). Nevertheless, it is notable that the residual stresses of the untreated material (see the results from $\pm 0.6 \mathrm{~mm}$ towards out of the DR trace) were significantly higher compressive, app. $-400 \mathrm{MPa}$ than those of the rest of the specimens. This can be an indication of higher compressive residual stresses generated by the polishing process, or residual stresses inherited from previous process chain steps.

On the other hand, the RS measured on the specimens treated with $40 \mathrm{MPa}$ pressure were similar for both pre-machining states, where those measured on the polished + DR specimen were at some places up to $100 \mathrm{MPa}$ higher compressive than these measured on the milled + DR specimen.

For all four specimens, the stress affected area largely exceeds the width of the DR trace. 
a) Milled (M) vs. polished (P), pressure variation

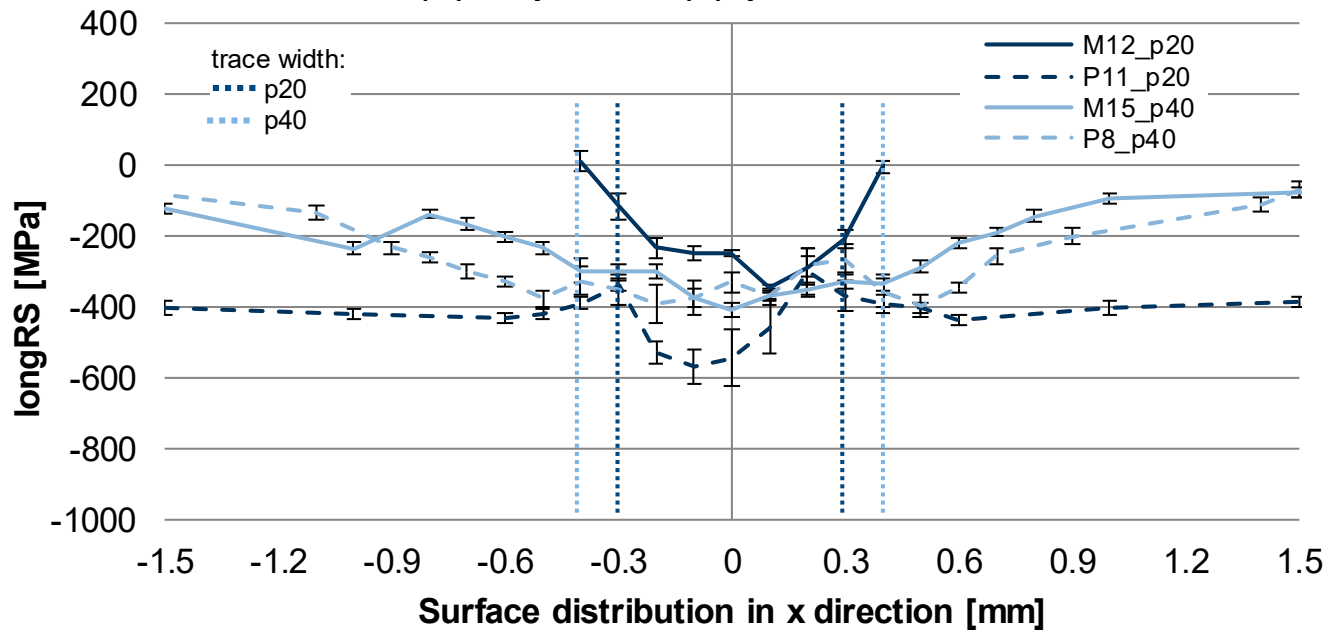

b)

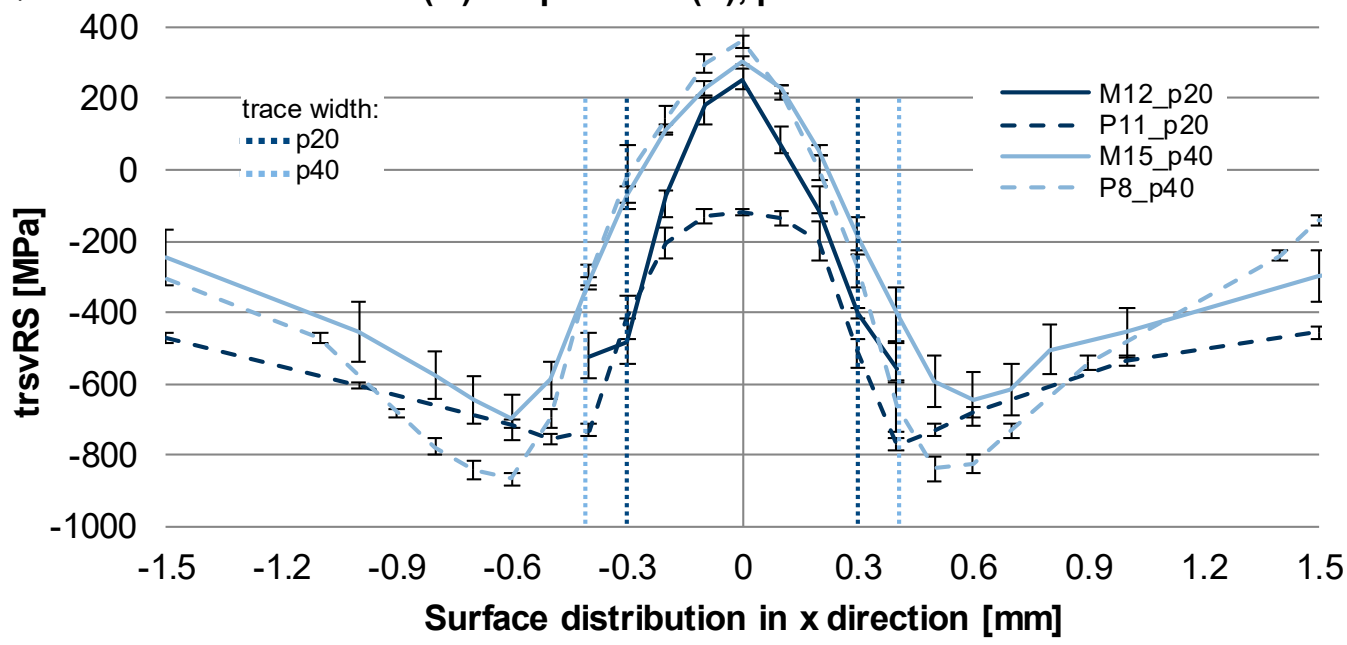

Figure 6. Residual stress surface distribution (measured with Seifert) after DR by different pre-machining states, i.e., milled and DR (designation " $\mathrm{M}$ ") or milled, polished and DR (designation " $\mathrm{P}$ ") and different DR pressure (designation " $\mathrm{p}^{\prime \prime}$ ); (a) longitudinal residual stresses (longRS) and (b) transverse residual stresses (trsvRS).

In Figure $6 \mathrm{~b}$ are plotted the RS in the transverse direction. The compressive RS maximum of up to $-900 \mathrm{MPa}$ (as the value almost approached the yield strength of the material) is located for all specimens out of the DR trace, where the polished specimens (P11 and P8) exhibited higher compressive RS than the milled specimens (M12 and M15). In the middle of the trace, the measured stresses for all specimens but P11 are moderate tensile. Here, the P11 differs again from the rest of the specimens, exhibiting slightly compressive instead of tensile stresses.

In general, it can be expected that in the transverse direction the compressive RS maximum was located out of the trace. This was an effect of the plastic deformation caused by the DR tool, expressed as material transverse stretching in the DR trace, where the stretched material was pushed in direction out of the trace, see [16]. In [17], it is discussed the typical RS profile of DR specimens, where it was stated that higher DR force/pressure, can lead to tensile RS on the surface.

Although, it remains unclear if the differing surface RS profile of the P11 specimen is due to inconsistency of the RS state from the pre-machining or it is an effect of the DR treatment. A superposition of the both factors is also possible.

The next process parameters' variation was done as fixing the DR pressure at $40 \mathrm{MPa}$ and varying the number of overturn (o.t.) or the overlapping percentage (o.l.). The pre-machining state (milled or 
milled + polished) was varied as well. For the specimen treated with DR with overlapping, the zero-x coordinate in the diagrams described the center of the overlapping trace. The surface RS distributions are plotted in Figure 7: Longitudinal direction-Figure 7a and transverse direction-Figure 7b. For both directions, it was expected that RS distribution should be symmetrical to the middle of the DR trace. In longitudinal direction, for two of the specimens (M19 and M22) this was not the case. Here, a lateral shift (up to $200 \mu \mathrm{m}$ ) of the stress profiles was observed, where it is not clear, is if the shifting was caused by a faulty DR treatment or if it is due to positioning misalignment during the stress determination. Regardless, the lateral shifting, it is visible that the DR treatment with seven overturns (M19 and P4) enhanced the maximal compressive RS in comparison with the single overturn (M15 and P8, Figure 6a) with 250-300 MPa. The stresses obtained by DR treatment with overlapping of 75\% (M22 and P2) do not significantly differ from those generated by the single trace DR (M15 and P8, Figure 6a).
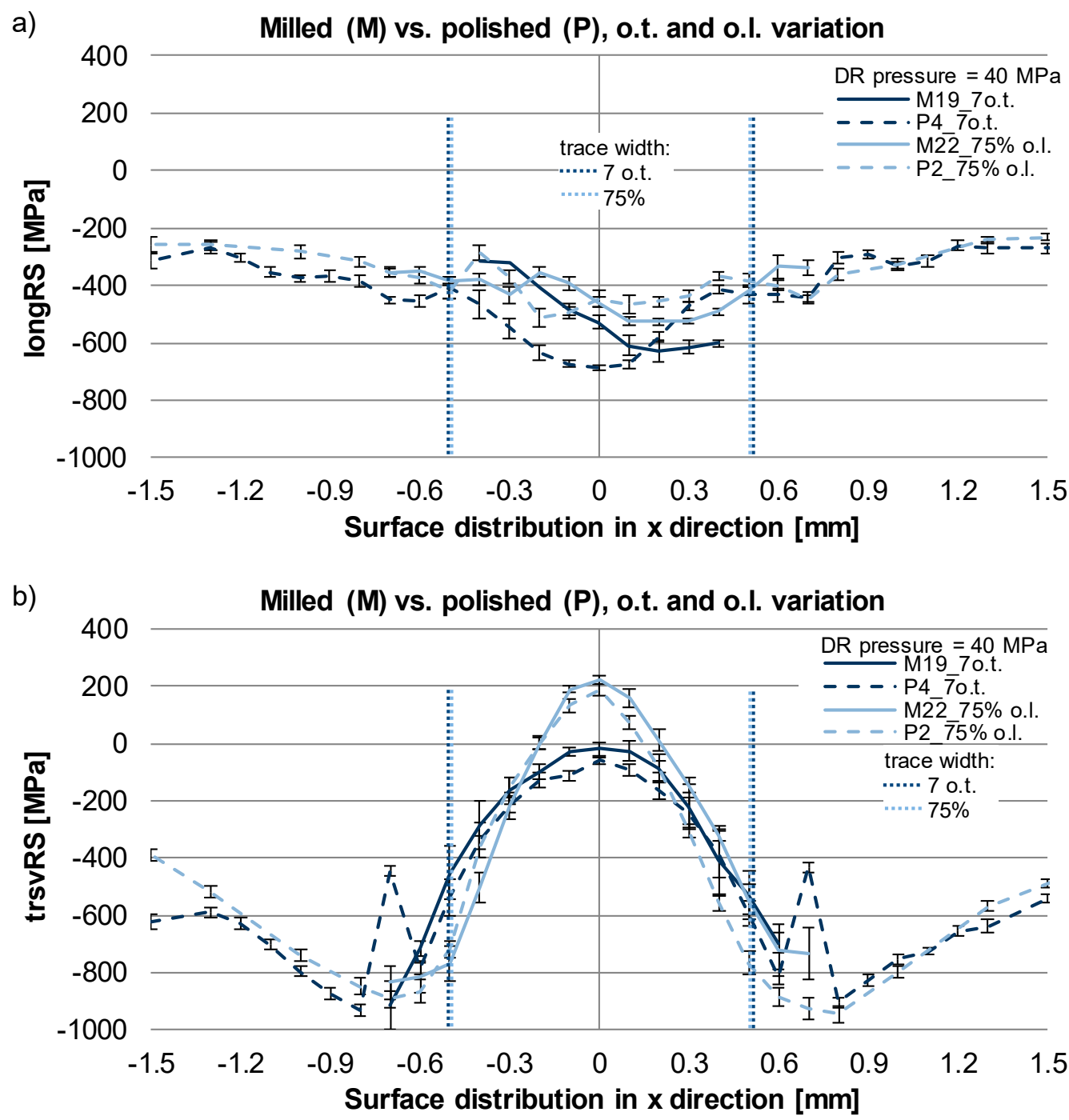

Figure 7. Residual stress surface distribution (measured with Seifert) after DR by different pre-machining states, i.e., milled and DR (designation " $\mathrm{M}$ ") or milled, polished and DR (designation " $\mathrm{P}$ "), overturn (o.t.) and overlapping (o.l.) variation; (a) longitudinal residual stresses (longRS) and (b) transverse residual stresses (trsvRS).

It was additionally observed that the different pre-machining (milling or milling + polishing) did not significantly affect the final RS distribution.

The surface RS profiles in transverse direction are shown in Figure $7 \mathrm{~b}$. Here, similarly to the results from Figure $6 \mathrm{~b}$, there is a presence of tensile, tending to zero residual stresses in the middle 
of the DR trace and the maximal compressive RS are located out of the DR trace. The DR treatment with seven overturns shifted the tensile stresses positioned in the middle of the DR trace in direction compression, to achieve a stress state near zero. In milled + polished + DR state, the treatment with seven overturns compared with a single overturn, the generated compressive RS were similar, reaching approximately -900 MPa. In contrary, the milling (w/o polishing) + DR treatment with seven overturns compared with single overturn delivered compressive RS out of the trace of approximately $-900 \mathrm{MPa}$ (approximately $200 \mathrm{MPa}$ higher compressive than the single overturn). This means that the multiple overturn DR treatment was, in this case, more favorable than the single overturn treatment.

Remarkable for the results of specimen P4 are the two measured values at $\mathrm{x}=-0.7 \mathrm{~mm}$ and at $x=0.7 \mathrm{~mm}$, which differed from all other results shown in Figure $7 \mathrm{~b}$. It is difficult to make an assumption about the origin of this local stress peaks but they are unlikely present due to local microstructure imperfection or treatment failure, as they are symmetrical to the trace's middle.

It was also observed that the stress profiles of specimens M19 and M22 were not shifted in the lateral direction, as the profiles measured in longitudinal direction but they are symmetrical to the middle of the DR trace and this can be an indication about misalignment of the X-ray primary beam.

The stress state of the specimens treated with 75\% overlapping (M22 and P2, Figure 7b) and of those treated without overlapping (M15 and P8, Figure 6b) was similar and the pre-machining (milled vs. milled + polished) did not affect significantly the final RS state.

\subsection{RS Depth Distribution After DR, Influence of the Pre-Machining}

After the characterization of the RS surface distribution achieved by different pre-machining states and varied DR process parameters, the RS depth profiles were obtained on the same specimens. It is important to point that the information for the RS depth distribution is, in general, crucial for the prediction of the fatigue behavior of the treated parts and cannot be substituted only by surface RS profiles determination. The so-called stress impact depth is an important characterization parameter, as the presence of deeper, not only high in amount, compressive RS can serve for retarding the propagation of existing cracks and can prevent cracks formation even by the presence of tensile RS on the surface. The definition "crack arrest/closure" describes this phenomenon [18].

In Figure 8 are shown the depth stress profiles of specimens treated with variable pre-machining and with DR pressure $20 \mathrm{MPa}$ or $40 \mathrm{MPa}$. The measuring points were defined in the middle of the $\mathrm{DR}$ trace in $+\mathrm{z}$ direction (see Figure 2 ) and the consecutive measured surfaces were obtained as the corresponding material layer was removed with means of electropolishing. The stress redistribution due to the material removal was considered but the measured values were not corrected, as the total thickness of the specimens (approximately $10 \mathrm{~mm}$ ) was much larger than the total layer removed (approximately $1.2 \mathrm{~mm}$ ). In addition, the highest measured values were always near the surface, where the stress redistribution due to the material removal was not substantial. Despite this, a test correction was done with the help of the mathematical formulations of Moore and Evans [19] and the difference between the corrected and not-corrected values did not exceed $50 \mathrm{MPa}$.

Figure 8a illustrates the RS in depth, measured in longitudinal direction for the specimens treated with $20 \mathrm{MPa}$ or $40 \mathrm{MPa}$ DR pressure and with variable pre-machining state. It can be observed that for all specimens, the magnitude of the compressive RS is similar (maximal difference $200 \mathrm{MPa}$ ) and the maximum is found about $75-100 \mu \mathrm{m}$ below the surface. In contrary, the stress impact depth is quite different, namely the stresses of the specimens treated with $40 \mathrm{MPa}$ pressure reach zero at approximately $0.7 \mathrm{~mm}$ depth, where those of the specimens treated with $20 \mathrm{MPa}$ tended towards zero at just $0.45 \mathrm{~mm}$ depth. Additionally, a discrepancy between the results for the different pre-machined states of approximately $300 \mathrm{MPa}$ was present only at the surface and at about $50 \mu \mathrm{m}$ depth diminished. 
a)

Milled (M) vs. polished (P), pressure variation

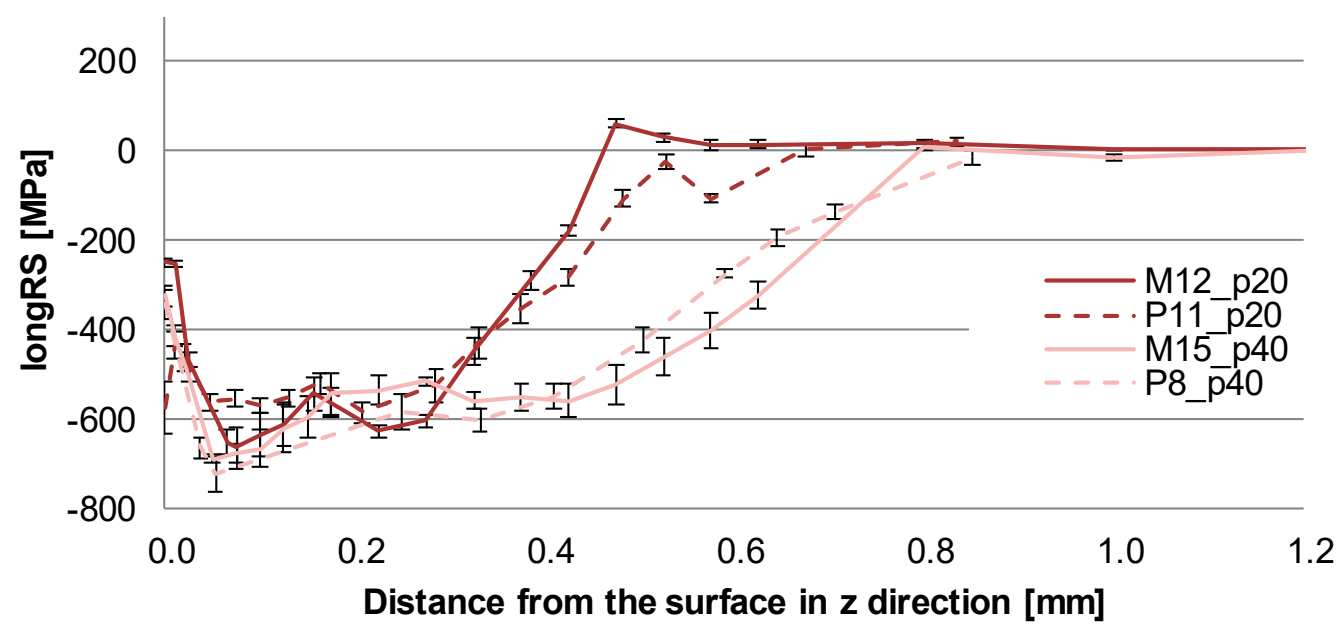

b) Milled $(M)$ vs. polished $(P)$, pressure variation

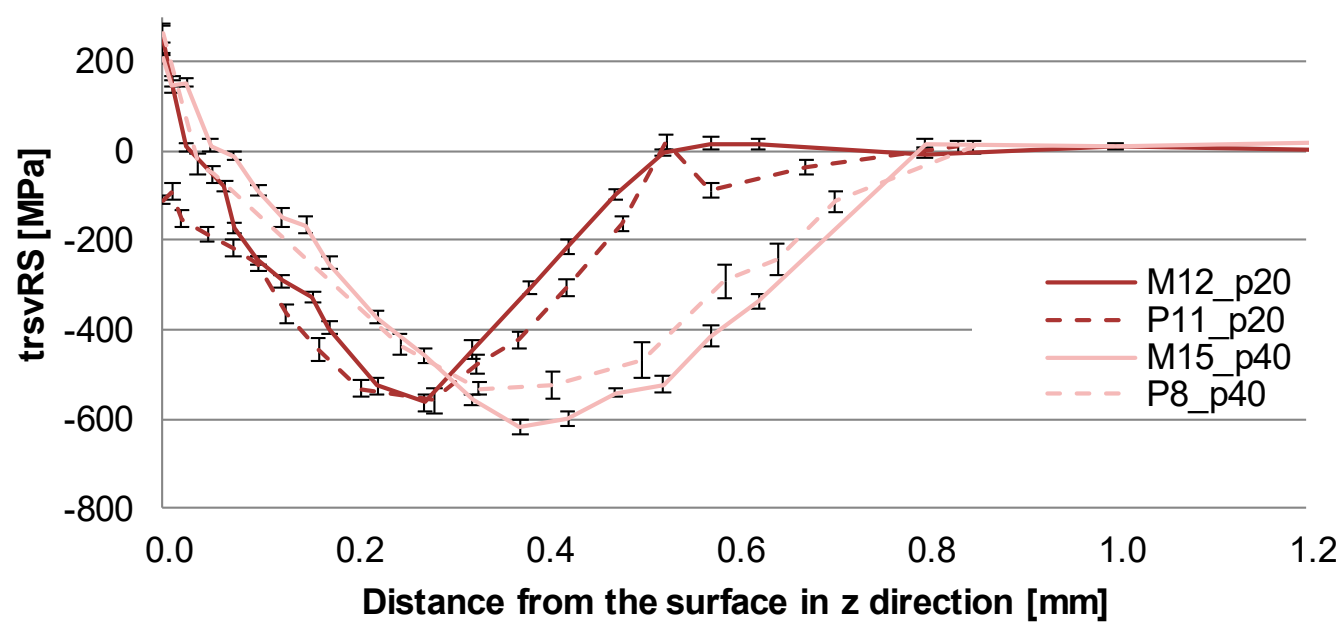

Figure 8. Residual stress depth distribution (measured with Seifert) after DR by different pre-machining states, i.e., milled and DR (designation " $\mathrm{M}$ ") or milled, polished and DR (designation " $\mathrm{P}$ ") and different DR pressure (designation " $\mathrm{p}$ "); (a) longitudinal residual stresses (longRS) and (b) transverse residual stresses (trsvRS).

In Figure $8 \mathrm{~b}$ are depicted the depth profiles of the stresses in transverse direction, by variable pre-machining state and variation of the DR pressure. Similarly to the results in Figure 8a, the higher DR pressure (M15 and P8) did not lead to enhancing the amount of the compressive RS but it positively affected the stress impact depth, increasing it with about $0.30 \mathrm{~mm}$ from $0.5 \mathrm{~mm}$ (M12 and P11) to $0.8 \mathrm{~mm}$ (M15 and P8). The transverse residual stress curve shape differs from this in longitudinal direction, having a maximum of the compressive residual stresses shifted into higher depth of $0.3 \mathrm{~mm}$ to $0.4 \mathrm{~mm}$. Notable is also the difference of the stress profiles for the specimens M12 and P11. Despite of the big discrepancy of the stresses on the surface (approximately $350 \mathrm{MPa}$ difference), this difference drastically diminished at about $75 \mu \mathrm{m}$ depth.

Typically for DR, the application of higher DR pressure lead to raising the stress impact depth in both longitudinal and transverse directions. The higher DR pressure lead to higher contact pressure between tool and work piece during processing. The higher contact pressure resulted in a thicker plastically deformed zone, which prevented the redistribution of the stresses after releasing the DR pressure, thus expanding the residual stress impact zone deeper into the material. 
The next results (see Figure 9) display the stress depth profiles in longitudinal (Figure 9a) and in transverse (Figure 9b) direction, by a fixed DR pressure of $40 \mathrm{MPa}$ and treatment with seven overturns (o.t.) or with $75 \%$ overlapping (o.1.).
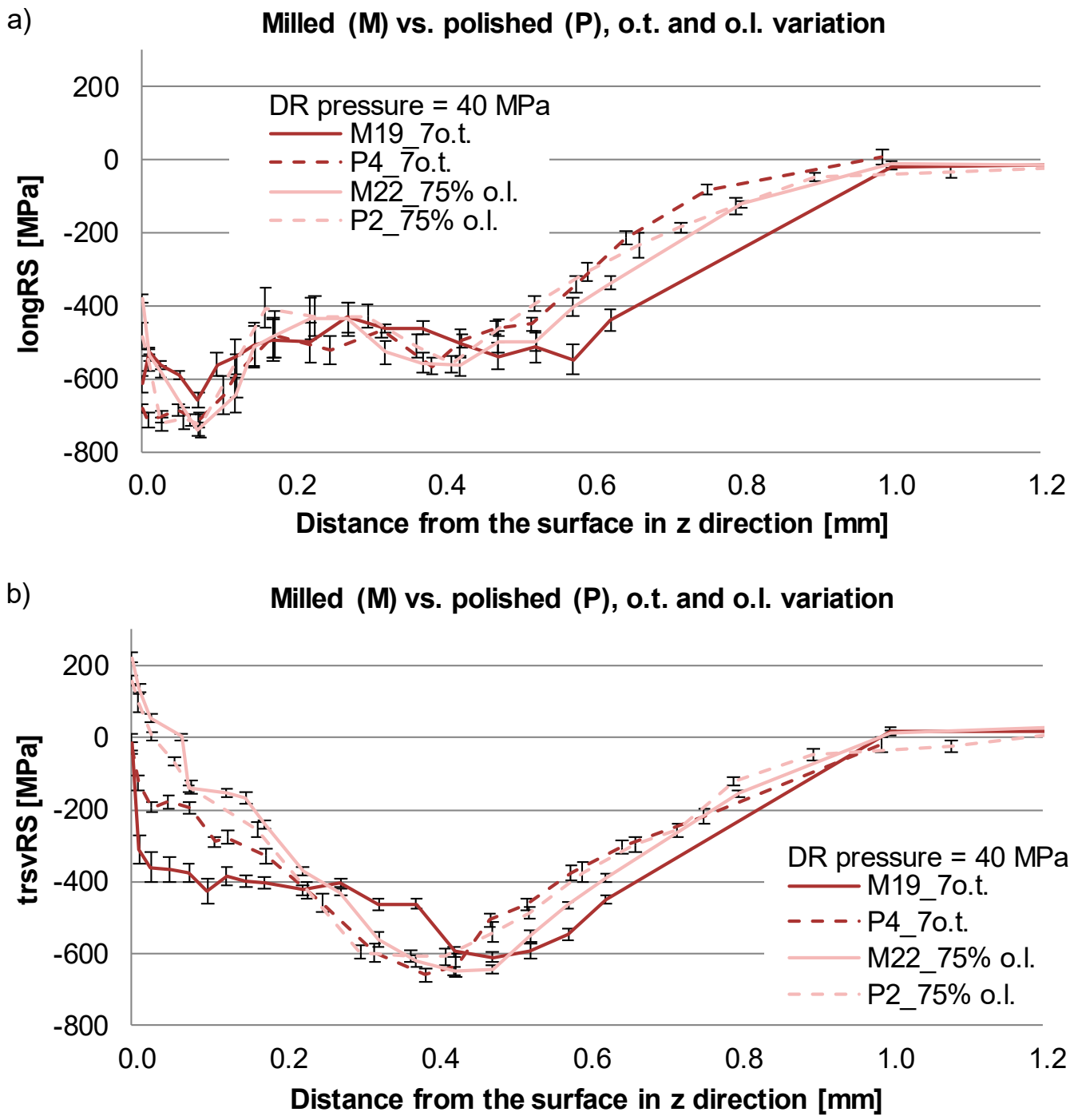

Figure 9. Residual stress depth distribution (measured with Seifert) after DR by different pre-machining states, i.e., milled and DR (designation " $\mathrm{M}$ ") or milled, polished and DR (designation " $\mathrm{P}$ "), overturn (o.t.) and overlapping (o.l.) variation; (a) longitudinal residual stresses (longRS) and (b) transverse residual stresses (trsvRS).

The depth distribution in the longitudinal direction is consistent for all four specimens and compared with the specimens M15 and P8 (see Figure 8a) the compressive RS are similar as position and as amount. Although, the stress impact depth reached about $1.0 \mathrm{~mm}$ for all four specimens (Figure 9a), where the M15 and P8 (see Figure 8a), treated also with 40 MPa DR pressure but only once and without overlapping have a smaller stress impact depth of $0.8 \mathrm{~mm}$. On the one hand, this observation confirms the favorable effect of the multiple-overturn DR treatment and on the other hand, it emphasizes the change in the RS state if applying DR with or without overlapping.

The same specimens were also measured in the transverse direction; the values are plotted in Figure 9b. Near the surface, the treatment with seven overturns (M19 and P4) compared with single overturn (M15 and P8, Figure 8b) generated near zero, instead of tensile stresses. In addition, the stresses developed more rapidly towards higher compression than those generated by the single 
overturn. The compressive stress maximum remained almost the same as amount but shifted to a higher depth with approximately $0.1 \mathrm{~mm}$ and the stress impact depth was greater, namely app. $1.0 \mathrm{~mm}$, compared with this generated by the single treatment of $0.8 \mathrm{~mm}$.

The depth profiles of the specimens M22 and P2 treated with 75\% overlapping were almost identical with those of M15 and P8 from Figure 8b (both without overlapping). The only difference is in the stress impact depth, which in case of treatment with overlapping reached $1.0 \mathrm{~mm}$, where the stress impact depth without overlapping was about $0.8 \mathrm{~mm}$.

When comparing the results of the different pre-machining states, the treated with $75 \%$ overlapping specimens (M22 and P2) exhibited almost identical RS depth profiles, while the specimens treated with seven overturns (M19 and P4) had RS depth profiles which moderately differ from each other.

Based on the comparisons made in this section, it can be concluded that the multiple overturn DR treatment and treatment with overlapping were more advantageous in terms of stress impact depth compared with single overturn treatment and without overlapping. The DR pressure did not have a significant impact on the compressive residual stress amount but affected greatly the stress impact depth with up to $0.3 \mathrm{~mm}$. The variation of the pre-machining did not lead to a significant tendency, as the depth profiles of milled + DR or milled + polished + DR specimens were either very similar or a moderate random discrepancy was available.

\section{Conclusions and Outlook}

In this paper, we discussed the impact of several deep rolling process parameters, the measurement conditions and the pre-machining on the residual stress state of deep rolled specimens.

First, investigated was the RS depth profile of milled specimens before the DR procedure. The RS profiles differed in the longitudinal and transverse direction but were very similar for the both specimens. Nevertheless, these differences diminished by a depth of $25 \mu \mathrm{m}$.

Next, the surface RS state after DR was determined using two different X-ray diffractometers, which possessed similar hardware features, using comparable measuring, and evaluation parameters. The results were in relatively good agreement, as in most cases, the differences between the values delivered by the both devices lay between $50 \mathrm{MPa}$ and $150 \mathrm{MPa}$. The discrepancy resulted assumable by a lateral positioning misalignment and by surface artefacts effects. This emphasized the importance of considering the measurement conditions as a disturbing factor, when investigating process interdependencies.

Thereafter, a wider surface area was investigated in order to characterize the whole area, where the DR process altered the RS state. The following DR process parameters were varied: DR pressure, number of overturns and percentage of overlapping; additionally, the process chain was variable, as some specimens were milled + deep rolled, while other were milled, polished and deep rolled. The RS affected zone widely exceeded the width of the DR trace, where for some specimens the determined RS were moderate compressive at even $1.2 \mathrm{~mm}$ from the DR trace middle. In addition, the RS distribution in longitudinal and transverse direction differed from each other, caused by the material's differing plastification flow direction during the DR treatment.

The pre-machining variation led to ambiguous results, as in several cases the milled + DR specimens compared with the milled + polished + DR specimens had very similar RS profiles, while two of the specimens (M12 and P11, Figure 6) exhibited a significant discrepancy. It was difficult to clarify the source of this discrepancy, as it could be the result of interdependencies between pre-machining, processing and measurement conditions. Still, the presence of moderate compressive $\mathrm{RS}$ in the untreated area was an indication of pre-processing influence.

The investigation of the DR process parameters illustrated some dependencies, e.g., the multiple overturn treatment compared to single overturn treatment led to higher compressive and lower tensile RS, thus making the final RS state more favorable. The treatment with overlapping compared to without overlapping led to very similar RS profiles. The influence of the variable DR pressure could not be clearly distinguished due to the ambiguous RS surface profiles by the varying pre-machining. 
Finally, RS depth profiles were determined, by varying the pre-machining state and the DR parameters (same as for the surface RS investigation). The gathered information was ever more important than this of the RS surface distribution, as the RS depth profile, has in general an impact that is more crucial on the fatigue strength of treated part, than the RS surface profile. The compressive stress impact depth plays an important role for the retarding of existing cracks during fatigue.

The influence of the applied DR pressure was as follows: For the investigated material state, higher DR pressure did not significantly affect the magnitude of the compressive RS but increased the stress impact depth with up to $0.3 \mathrm{~mm}$ means up to $60 \%$. This was valid for both longitudinal and transverse directions. The comparison between the treatment with seven overturns (no overlapping), the one with single overturn but with $75 \%$ overlapping, and the one with a single overturn without overlapping (all with fixed DR pressure at $40 \mathrm{MPa}$ ) showed the following tendency: The magnitude of the compressive RS remained the same but the stress impact depth was greater (by approximately $0.2 \mathrm{~mm}$ ) with the treatment with seven overturns and by the one with $75 \%$ overlapping.

The maximum compressive RS of the RS depth profiles reached as amount approximately $60 \%$ to $75 \%$ of the material's yield strength and the generated stress impact depth was up to $1.00 \mathrm{~mm}$.

Noticeable was the variation of the pre-machining, which in contrary to the results from the surface RS investigation showed here less impact on the RS depth profiles and did not lead to some systematic dependency.

The findings gained from this study will be used to fully verify the finite element model of the DR process, as presented in $[13,14]$.

Author Contributions: Conceptualization, N.L., D.B. and J.E.H.; methodology, N.L., D.B. and J.E.H.; data curation, L.K., J.F., T.C. and J.P.; writing—original draft preparation, N.L. and J.E.H.; writing—review and editing, N.L., D.B. and J.E.H.; supervision, D.B. and J.E.H.; project administration, N.L.

Funding: This research received no external funding.

Acknowledgments: This research was kindly supported by the ECOROLL Company in Celle, Germany, who performed the deep rolling treatments. Special thanks to the colleagues from the Chair of functional materials at the Saarland University for providing the X-ray diffractometer PANalytical Empyrean and for the helpful scientific insight and expertise that greatly supported this research.

Conflicts of Interest: The authors declare no conflict of interest.

\section{References}

1. Föppl, O. Das Drücken der Oberflächen von Bauteilen aus Stahl. Stahl Eisen 1929, 49, 575-577.

2. Thum, A.; Bautz, W. Ursachen der Steigerung der Dauerhaltbarkeit gedrückter Stäbe. Forsch. Ing. 1935, 6, 121. [CrossRef]

3. Horger, O.J. Effect of the surface rolling on the fatigue strength of steel. J. Appl. Mech. 1936, 58, 91-98.

4. Schulze, V. Surface layer states after mechanical surface treatments. In Modern Mechanical Surface Treatment-States, Stability, Effects; WILEY-VCH Verlag GmbH \& Co.: Weinheim, Germany, 2006; p. 89.

5. Michaud, H.; Sprauel, J.M.; Galzy, F. The residual stresses generated by deep rolling and their stability in fatigue \& application to deep-rolled crankshafts. Mater. Sci. Forum 2006, 524-525, 45-50.

6. Website ECOROLL Company. Deep Rolling Two Areas of an Aircraft Wheel Rim, Applications. Aerospace/Energy Technology. Available online: http://www.ecoroll.de/en/applications/aerospaceenergytechnology/aircraft-wheel-rim.html (accessed on 3 May 2019).

7. Bäcker, V.; Klocke, F.; Wegner, H.; Timmer, A.; Grzhibovskis, R.; Rjasanow, S. Analysis of the deep rolling process on turbine blades using the FEM/BEM-Coupling. IOP Conf. Ser. Mater. Sci. Eng. 2010, 10, 1-10. [CrossRef]

8. Jung, U. FEM-Simulation und Experimentelle Optimierung des Festwalzens Bauteilähnlicher Proben Unterschiedlicher Größe, Dissertation; TU Darmstadt: Darmstadt, Germany, 1996.

9. Liou, J.J.; El-Wardany, T.I. Finite Element Analysis of Residual Stress in Ti-6Al-4V Alloy Plate Induced by Deep Rolling Process under Complex Roller Path. Int. J. Manuf. Eng. 2014, 2014, 1-15. [CrossRef]

10. Achmus, C. Messung und Berechnung des Randschichtzustands Komplexer Bauteile Nach Dem Festwalzen, Dissertation; TU Braunschweig: Braunschweig, Germany, 1999. 
11. Majzoobi, G.H. Experimental and numerical studies on the effect of deep rolling on bending fretting fatigue resistance of Al7075. Int. J. Adv. Manuf. Technol. 2016, 82, 2137-2148. [CrossRef]

12. Lim, A.; Castagne, S.; Wong, C.C. Quasi-static process modeling of deep cold rolling of Ti-6Al-4V. Int. Conf. Residual Stress 2016, 2, 7-12.

13. Lyubenova, N.; Baehre, D. Finite element modelling and investigation of the process parameters in deep rolling of AISI 4140 steel. J. Mater. Sci. Eng. B 2015, 5, 277-287.

14. Lyubenova, N.; Bähre, D. Investigation of the surface residual stresses in single and multiple trace deep rolling on flat AISI 4140 specimens. In Proceedings of the 13th International Conference on Shot Peening, Montreal, QB, Canada, 18-21 September 2017; pp. 428-433.

15. Hoffmann, J.E. Der Einfluss Fertigungsbedingter Eigenspannungen Auf Das Biegewechselverhalten Von Glatten und Gekerbten Proben Aus Ck 45 in Verschiedenen Werkstoffzuständen, Dissertation; University Karlsruhe: Karlsruhe, Germany, 1984.

16. Schulze, V. Mechanische Oberflächenbehandlungen. In Proceedings of the DGM Symposium Surface Engineering, Dresden, Germany, 16 September 2015.

17. Berstein, G. Festwalzen und Schwingfestigkeit. Z. Werkst. 1982, 13, 103-109. [CrossRef]

18. Gardin, C.; Courtin, S.; Bézine, G.; Bertheau, D.; Hamouda, H.B.H. Crack propagation in compressive residual stress fields of crankshafts: Experimental study and numerical simulation. Wit Trans. Eng. Sci. 2005, 49, 231-240.

19. Moore, M.; Evans, W. Mathematical Correction for Stress in Removed Layers in X-Ray Diffraction Residual Stress Analysis. In SAE Technical Paper 580035; SAE International: Troy, MI, USA, 1958; pp. 340-345.

(C) 2019 by the authors. Licensee MDPI, Basel, Switzerland. This article is an open access article distributed under the terms and conditions of the Creative Commons Attribution (CC BY) license (http://creativecommons.org/licenses/by/4.0/). 